\title{
Solid State NMR Applied to Evaluate Fibers Cotton
}

\author{
Adriano Alves Passos ${ }^{1,2}$, Roberto Pinto Cucinelli Neto', Maria Inês Bruno Tavares ${ }^{1}$ \\ ${ }^{1}$ Instituto de Macromoléculas Professora Eloisa Mano da Universidade Federal do Rio de Janeiro, Ilha do Fundão, RJ, Brazil \\ ${ }^{2}$ Instituto Senai de Inovação em Biossintéticos e Fibras - SENAI CETIQT, Rio de Janeiro, RJ, Brazil \\ Email:mibt@ima.ufrj.br
}

How to cite this paper: Passos, A.A., Neto, R.P.C. and Tavares, M.I.B. (2020) Solid State NMR Applied to Evaluate Fibers Cotton. Materials Sciences and Applications, 11, 591-599.

https://doi.org/10.4236/msa.2020.118039

Received: November 22, 2019

Accepted: August 25, 2020

Published: August 28, 2020

Copyright (c) 2020 by author(s) and Scientific Research Publishing Inc. This work is licensed under the Creative Commons Attribution International License (CC BY 4.0).

http://creativecommons.org/licenses/by/4.0/

\begin{abstract}
The evaluation of cotton fibers from Nuclear Magnetic Resonance (NMR) in solid state using high and low-field showed to be a good alternative to evaluate these materials. The main objective of this work was to use the solid-state NMR techniques to accompany the fibers nature, size and morphology to have a direct method to evaluate cotton fibers maturity. We could conclude that the solid-state NMR techniques are good source to evaluate the molecular behavior of cotton short and long fibers and give important information on sample's morphology, indicating that this technique can be used to distinguish the size of cotton fibers.
\end{abstract}

\section{Keywords}

Cotton Fibers, NMR, Maturity

\section{Introduction}

Cotton fibers size, texture, maturity, and others physical characteristics are of fundamental interest when these materials are used to obtain new products, as especial cloths [1] [2], among others. These characteristics influence and or infer the quality of the new materials and of course in the price of the final product [3] [4].

Due to the great importance of these fibers, several studies are normally done. The measurements in the Uster Advanced Fiber Information System (AFIS) and High Volume Instruments (HVI) give parameters that are the most used methods to obtain the primary and important responses on cotton fibers maturity classification [2]. To evaluate the maturity degree of Micronaire index (MIC) is used to determine the relation of fineness/maturity of the fiber. The fineness is 
the mass of the fiber per unit length (title), usually expressed in militex (mtex). Maturity is the degree of maturity of a cotton fiber, which is indicated by the thickness of the cell wall in relation to the diameter of the fiber [5]. The price of cotton fiber is priced on the stock exchange on the world market. Many times these batches are priced with the low value, since the rounds have the satisfactory properties for processing. Maturity, which is largely determined by growing conditions, can be defined as the relative wall thickness (the area of the cell wall to that of a circle with the same perimeter as the fiber, or the ratio of the cell wall thickness to the overall "diameter" of the fiber).

The solid-state NMR techniques show to be good tool to analyze and identify the fibers types such as cotton samples. Knowing that solid-state NMR basic techniques are good tool to evaluate the materials in their own state, these techniques can be applied to the fibers study. Magic angle spinning (MAS) and cross-polarization magic angle spinning (CPMAS) techniques give response on samples chemical structure and domain structure [6]. The variable contact-time experiment (VCT) informs on sample molecular dynamic evaluation and the proton spin-lattice relaxation time in the rotating frame $\left(\mathrm{T}_{1} \mathrm{H} \rho\right)$ permits to characterize the intermolecular interactions forces and classify the samples according to their molecular dynamics, according to their molecular movements since this parameter are sensitive to the movements in the tens of kilohertz with domain size in the range of 1 to $4 \mathrm{~nm}$ [6] [7]. Thus, in this work, we used carbon-13 $\left({ }^{13} \mathrm{C}\right)$ VCT to determine the $\mathrm{T}_{1} \mathrm{H} \rho$ values from each resolved carbon to analyze the cotton fibers types according to their molecular structure and dynamics. Knowing that this parameter informs on the molecular movements in the $\mathrm{MHz}$ range and domain size varied from 25 to $50 \mathrm{~nm}$, this study determined also the values of proton spin-lattice (with a time constant $\mathrm{T}_{1} \mathrm{H}$ ) of the samples using a low-field NMR spectrometer [8]. According to this statement, it was analyzed carbon-13 $\left({ }^{13} \mathrm{C}\right)$ employing MAS, CPMAS, VCT and the determination of $\mathrm{T}_{1} \mathrm{H} \rho$ to deeply analyze the cotton fibers molecular structure and dynamics. To complement the analyses, it was also determined the values of proton spin-lattice $\left(\mathrm{T}_{1} \mathrm{H}\right)$ of the samples using a low-field NMR spectrometer [9].

Thus, according to the explanation described before, the main purpose of this work was to apply the solid-state NMR techniques using high and low-field (relaxometry) NMR to evaluate the short and long cotton fibers, and obtain information on the correlation of this parameter to the fibers structural organization.

\section{Experimental}

\subsection{Materials}

Cotton fibers standard were supplied by SENAI CETIQT, which have same specifications that are listed in Table 1. The fibers were used as received.

Figure 1 exhibits the short and long fibers of cotton studied in this work, measured in the 530 Fibrograph, model Spinlab, is an apparatus that measures the length of the fiber after passage of the same by a comb so that the sample is 
Table 1. Cotton fibers standard specifications.

\begin{tabular}{cccccc}
\hline Sample & Type fiber & Micronaire & $\begin{array}{c}\text { Fiber Strength } \\
\text { measurement }\end{array}$ & $\begin{array}{c}\text { Upper } \\
\text { half }\end{array}$ & $\begin{array}{c}\text { Fiber length } \\
\text { measurement } \\
\text { Uniformity }\end{array}$ \\
\hline American upland & Long-strong & 4.27 & 30.4 & 1.154 & 83.6 \\
American Upland & Short-weak & 3.87 & 19.2 & 0.882 & 78.2 \\
\hline
\end{tabular}
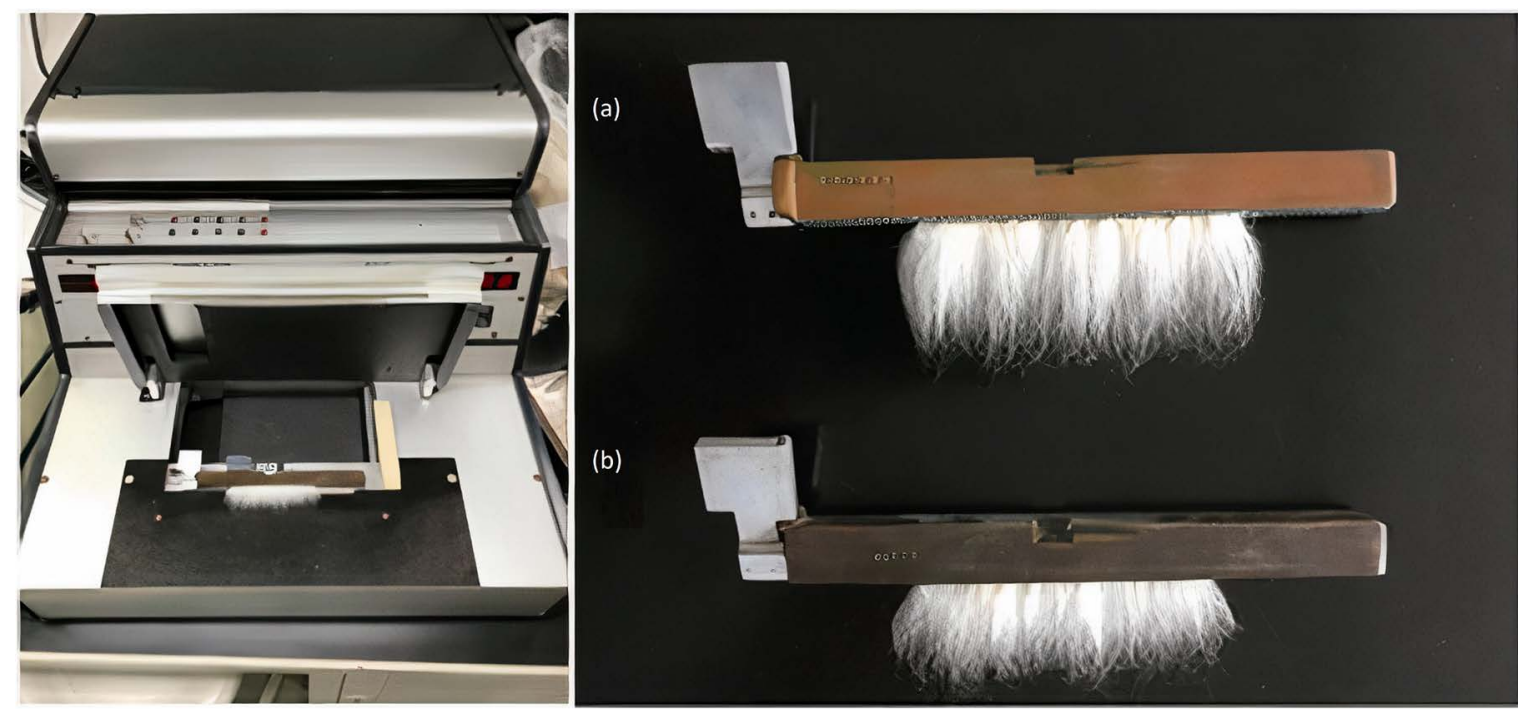

Figure 1. Fiber Strength measurement (a) Long strong with $30.5 \mathrm{~mm}$ and (b) Short-weak with $19.2 \mathrm{~mm}$.

evaluate by a sensor that measures the average of the fiber lengths of the standard sample.

\subsection{NMR Experiments}

\section{High-field NMR}

All solid-state NMR spectra were obtained on a Bruker spectrometer 7.04 Tesla, operating at $75.4 \mathrm{MHz}$ for ${ }^{13} \mathrm{C}$ nuclei. The samples were conditioned before been analyzed. The samples were packed in a $4 \mathrm{~mm}$ zirconia rotor that was spun in the magic angle at about $8 \mathrm{kHz}$ for both nuclei. The applied techniques to analyze the samples were: ${ }^{13} \mathrm{C}$ cross-polarization magic angle spinning (CPMAS) and ${ }^{13} \mathrm{C}$ variable contact time (VCT). The ${ }^{13} \mathrm{C}$ CPMAS were obtained from the VCT experiment, which were carried out using $4 \mathrm{~s}$ of recycle delay with the increase of contact time varying from 200 to $8000 \mu \mathrm{s}$. From this experiment, it was also determined the proton spin-lattice relaxation time in the rotating frame $\left(\mathrm{T}_{1 \rho} \mathrm{H}\right)$ for each resolved carbon. Hexamethyl benzene (HMB) was used as external standard; the methyl carbons were assigned as $17.3 \mathrm{ppm}$.

\section{Low-field NMR}

Determination of proton-spin-lattice relaxation time

The measurements of proton-spin-lattice relaxation time were performed in a Maran Ultra spectrometer with an electromagnetic field of $0.54 \mathrm{~T}$ (Larmor frequency corresponding to $23.4 \mathrm{MHz}$ for the proton), in a NMR tube with an in- 
ternal diameter of $18 \mathrm{~mm}$. The samples were conditioned before been analyzed. The analyses temperature was $30^{\circ} \mathrm{C}$. The excitation pulse $90^{\circ}$ was automatically calibrated to 7.5 microseconds of duration. The longitudinal $\left(\mathrm{T}_{1}\right)$ relaxation time was measured by inversion-recovery pulse sequence, with a range of 40 tau varying from 100 to $5 \mathrm{~s}$, with $5 \mathrm{~s}$ of recycle delay and with 4 number of scans for each tau.

\section{Results and Discussion}

Analyzing the solid-state ${ }^{13} \mathrm{C}$ NMR CPMAS spectra of the cotton containing short and long fibers, it was observed that (Figure 2) there was a small difference in both fibers in relation to the chemical shift and signal base line and shape especially for the 75 to $77 \mathrm{ppm}$ region, referred to the $\mathrm{CH}-\mathrm{O}$ carbon type. According to the assignments of all types of resolved carbons in the C-13 NMR spectra the values of chemical shift and the profile of C-13 NMR spectra for both cotton fibers are associated to cellulose type I [10].

The VCT experiment (Figure 3) exhibits the decay of each resolved carbon from the samples, such as: C-O-C (from 92 to $109 \mathrm{ppm}$ ) CH-O (81 ppm derived from rigid part) $\mathrm{CH}-\mathrm{O}$ (75- $79 \mathrm{ppm}$ due to main chain) and $\mathrm{CH}_{2} \mathrm{O}$ (65 to 68 ppm).

It can be observed that the decay of long fiber sample is deeper than for the short fiber sample; which is a consequence of fiber chains organization and domain size. Table 2 shows the values of $\mathrm{T}_{1 \rho} \mathrm{H}$ for both short and long fiber cottons, form the VCT decay for each resolved carbon.

From $\mathrm{T}_{1 \rho} \mathrm{H}$ values it can be evaluated that for short fibers the values of this parameter are lower comparing to long fiber cottons, which is a consequence of chains size and of course due to the molecular organization. The long fibers present values of this parameter a little higher due to the collective movement of the fibers chains. Both fibers present certain homogeneity in the relaxation values, because of the samples have the same nature. Therefore, the long fibers present better homogeneity. Comparing decay of each $\mathrm{T}_{1 \rho} \mathrm{H}$ curve for each parameter shows that the decay curves for cotton short fibers is deeper comparing to cotton long fibers.

The measurements of $\mathrm{T}_{1} \mathrm{H}$ (Table 3) was used to evaluate the behavior of the fibers in relation to all type of hydrogen spin-nuclear population, and the domains that constitute the fibers.

From Table 4, it was not possible to distinguish the collective movements of fibers chains, according to their size and specifications. Thus, to obtain more and important information from cotton fibers the $\mathrm{T}_{1} \mathrm{H}$ parameter was measured in different conditions. Since the difference of each fiber type was not so sensible at the measurements at room temperature, due to the fact that for the NMR sensibility is low. Thus, the relaxation data was measured with an increase in the temperature. Table 3 shows the values of relaxation parameter after the measurements with the increase of temperature and is presented in Table 5. 
Short and Weak Cotton Fiber

(a)
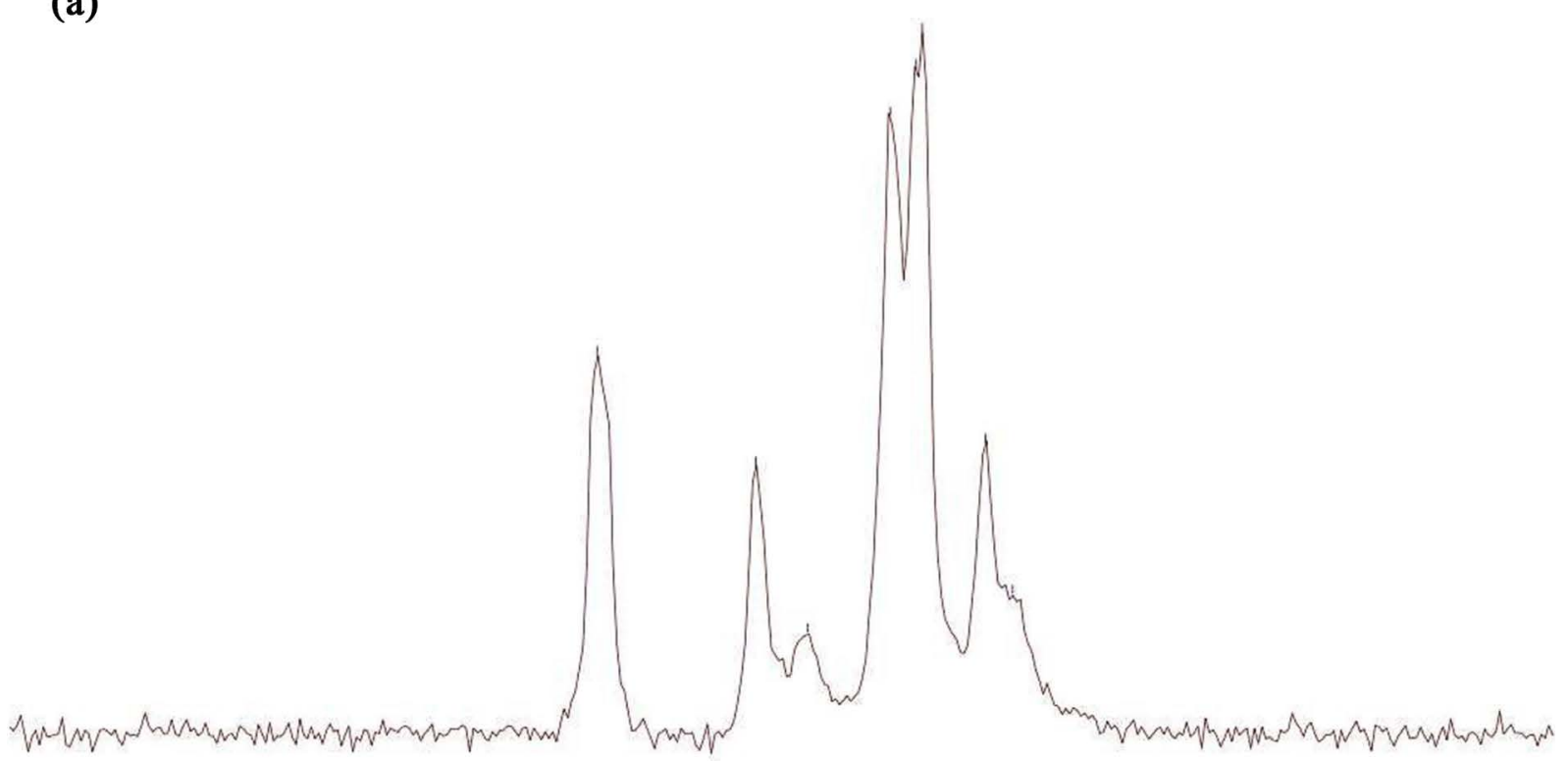

\begin{tabular}{|c|c|c|c|c|c|c|c|c|c|c|c|c|c|c|}
\hline 160 & 150 & 140 & 130 & 120 & 110 & 100 & $\begin{array}{c}90 \\
\mathrm{f} 1(\mathrm{ppm})\end{array}$ & 80 & 70 & 60 & 50 & 40 & 30 & 20 \\
\hline
\end{tabular}

Long and Strong Cotton Fiber

(b)

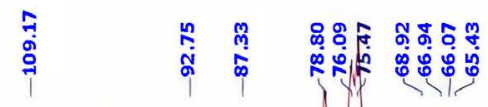

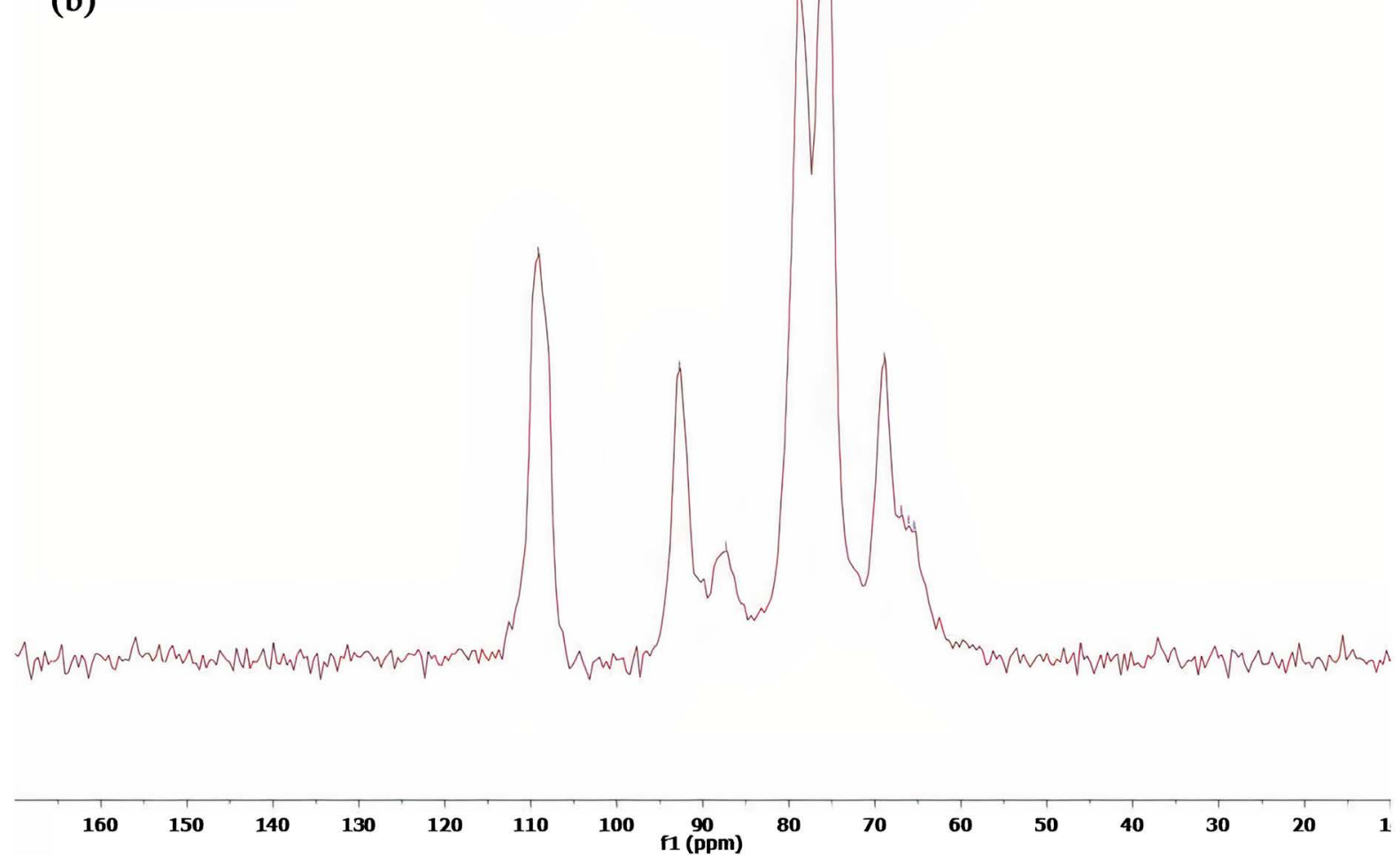

Figure 2. Solid-state ${ }^{13} \mathrm{C}$ NMR CPMAS spectra of the cotton containing short and long fibers. 


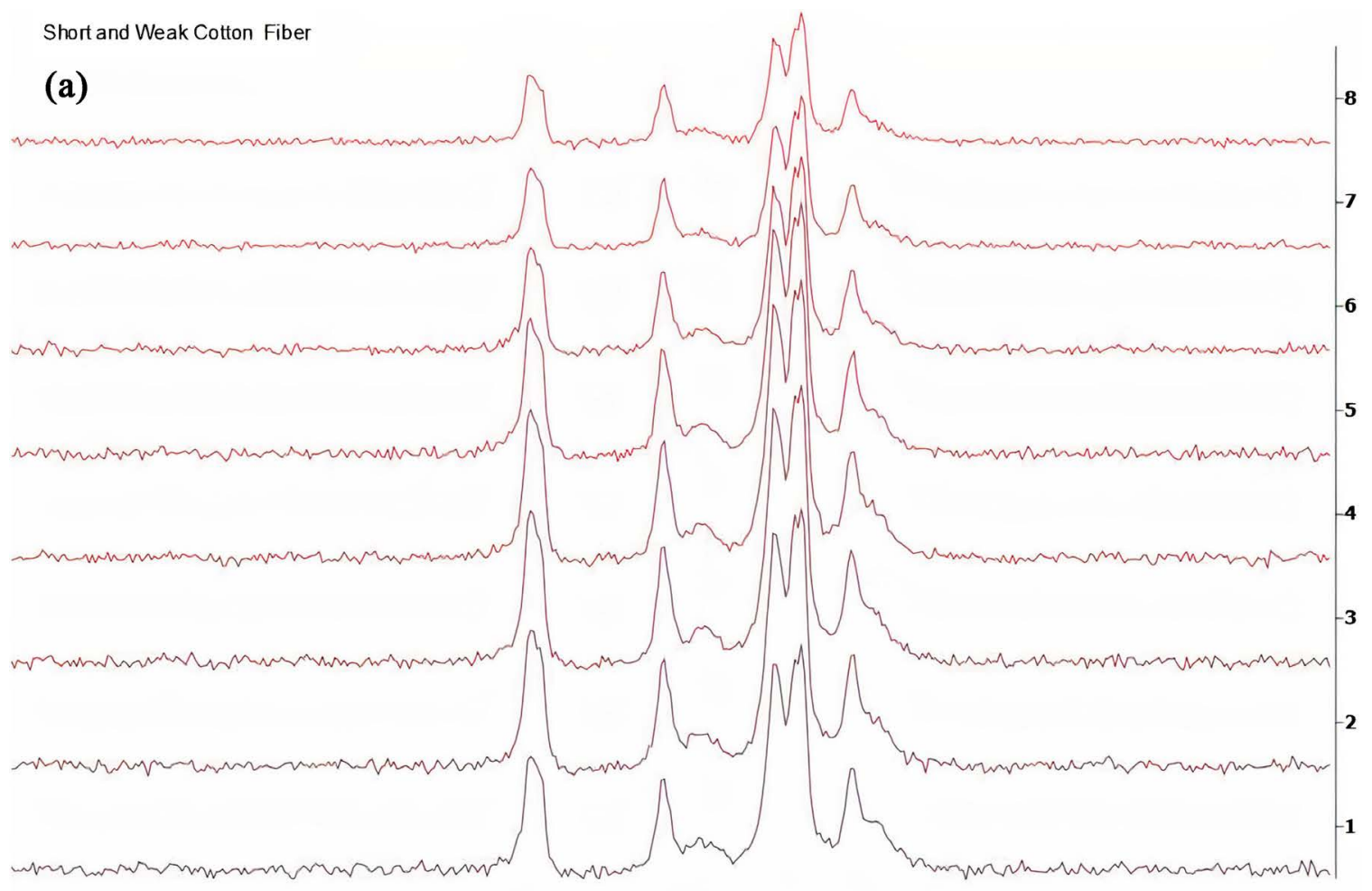

\begin{tabular}{llllllllllllllll}
\hline 170 & 160 & 150 & 140 & 130 & 120 & 110 & $100 \underset{f(p)}{90}(\mathrm{pm})$ & 80 & 70 & 60 & 50 & 40 & 30 & 20 & 10
\end{tabular}

Long and Strong Cotton Fiber

(b)
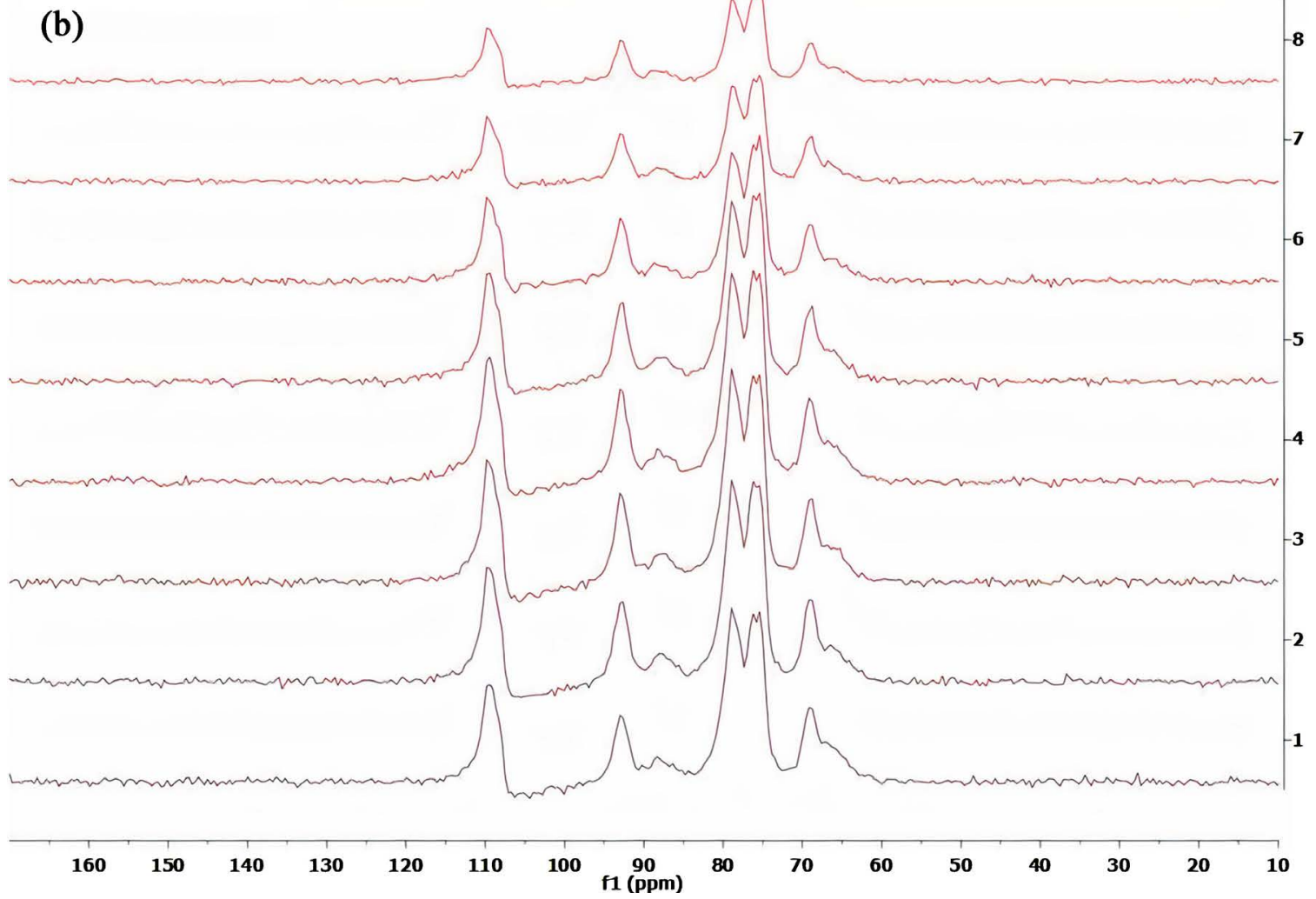

Figure 3. Series of C-13 CPMAS NMR - VCT experiment for both short and weak cotton fibers and long and strong cotton fibers. 
Table 2. $\mathrm{T}_{1 \rho} \mathrm{H}$ values for both short and long fiber cottons at room temperature.

\begin{tabular}{cccccc}
\hline & \multicolumn{5}{c}{$\mathrm{T}_{1 \rho} \mathrm{H}(\mathrm{ms})$} \\
\cline { 2 - 6 } Fiber & $\mathbf{1 0 9}$ & $\mathbf{9 2}$ & $\mathbf{7 8}$ & 75 & $\mathbf{6 8} \boldsymbol{\delta}(\mathrm{ppm})$ \\
& $\mathrm{C}-\mathrm{O}-\mathrm{C}$ & $\mathrm{C}-\mathrm{O}-\mathrm{C}$ & $\mathrm{CH}-\mathrm{O}$ & $\mathrm{CH}-\mathrm{O}$ & $\mathrm{CH}_{2}-\mathrm{O}$ \\
\hline \multirow{2}{*}{ Short } & 4.0 & 3.6 & 5.0 & 3.0 & 4.5 \\
Long & 5.5 & 5.0 & 4.0 & 4.0 & 4.0 \\
\hline
\end{tabular}

Table 3. $\mathrm{T}_{1} \mathrm{H}$ values for both short and long fiber cottons at room temperature $\left(25^{\circ} \mathrm{C}\right)$.

\begin{tabular}{ccc}
\hline & \multicolumn{2}{c}{$\mathrm{T}_{1} \mathrm{H}(\mathrm{ms})$} \\
\cline { 2 - 3 } Sample fiber cotton & $\mathrm{T}_{1,1} \mathrm{H}$ & $\mathrm{T}_{1,2} \mathrm{H}$ \\
\hline Short Weak & 12 & 129 \\
Long Strong & 12 & 129 \\
\hline
\end{tabular}

Table 4. $\mathrm{T}_{1} \mathrm{H}$ values for both short and long fiber cottons at $30^{\circ} \mathrm{C}$.

\begin{tabular}{cccc}
\hline \multirow{2}{*}{ Sample fiber cotton } & \multicolumn{3}{c}{$\mathrm{T}_{1} \mathrm{H}(\mathrm{ms})$} \\
\cline { 2 - 4 } & $\mathrm{T}_{1,1} \mathrm{H}$ & $\mathrm{T}_{1,2} \mathrm{H}$ & $\mathrm{T}_{1,3} \mathrm{H}$ \\
\hline Short Weak & 13 & 74 & 175 \\
Long Strong & 14 & 72 & 217 \\
\hline
\end{tabular}

Table 5. $\mathrm{T}_{1} \mathrm{H}$ values for both short and long fiber cottons at high temperature.

\begin{tabular}{ccc}
\hline \multirow{2}{*}{ Sample fiber cotton } & \multicolumn{2}{c}{$\mathrm{T}_{1} \mathrm{H}(\mathrm{ms})$} \\
\cline { 2 - 3 } & $\mathrm{T}_{1,1} \mathrm{H}$ & $\mathrm{T}_{1,2} \mathrm{H}$ \\
\hline Short Weak & 8 & 189 \\
Long Strong & 0.8 & 259 \\
\hline
\end{tabular}

It was noted that from $\mathrm{T}_{1} \mathrm{H}$ parameter the long cotton fiber presents higher value of this parameter for the fibers domains, due to the stronger intermolecular interaction, which comes from the fibers size and molecular organization and also the molecular collective movements are slower than the one from derived from short cotton fibers. The short cotton fibers the opposite behavior was found; confirming that these fibers are weaker comparing to long fiber cottons, because of physical characteristics being different in both fibers, which is in accordance with the Micronaire index.

Figure 4 shows the comparison of domains relaxation curves for the samples at room temperature $\left(25^{\circ} \mathrm{C}\right)$ and at high temperature $\left(120^{\circ} \mathrm{C}\right)$. From the results it can be seen a strong difference in the data an domain relaxation distribution and form, which is a strong evidence that the fibers organization are different and in the long fiber there is more intermolecular interaction that promotes changes in the sample organization influencing in the sample properties. The small domains with low value of relaxation data comes from the water humidity due to the chemical hydrophilic nature of the sample. 


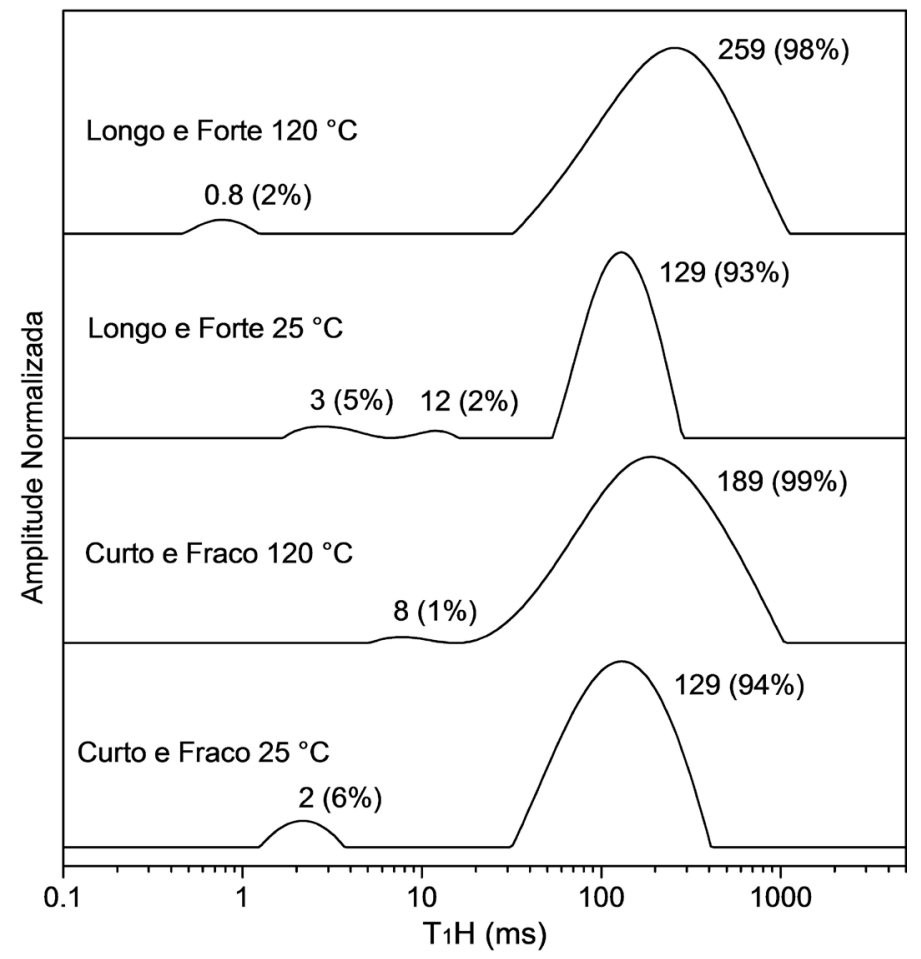

Figure 4. Domains Distribution of Strong and weak cotton fibers a $25^{\circ} \mathrm{C}$ and $120^{\circ} \mathrm{C}$.

\section{Conclusion}

According to all results, we can conclude that the solid-state NMR techniques and relaxometry are good source to evaluate the molecular behavior of cotton short and long fibers and give important information on the samples morphology, indicating that this technique can be used to distinguish the size of cotton fibers. The NMR results measured for both solid state NMR and relaxometry are techniques that can be able to give important response on sample morphology, since the solid-state analyses allow to evaluate the spatial intermolecular interactions according to the chains proximity.

\section{Acknowledgements}

This study was financed in part by the Coordenação de Aperfeiçoamento de Pessoal de Nível Superior-Brasil (CAPES)—Finance Code 001. And the authors would like to thanks the CNPq and FAPERJ Brazilian agencies for the grants.

\section{Conflicts of Interest}

The authors declare no conflicts of interest regarding the publication of this paper.

\section{References}

[1] Tyagi, P. (2013) North Carolina State University. https://repository.lib.ncsu.edu/handle/1840.16/8769

[2] Fassihi, A. and Hunter, L. (2016) Application of an Automatic Yarn Dismantler to 
Track Changes in Cotton Fiber Properties during Full Scale Processing of Cotton into Carded Yarn. Journal of Natural Fibers, 13, 555-564.

https://doi.org/10.1080/15440478.2015.1083925

[3] Gama, J.S.N., Júnior, L.R.P., Pereira, F.J.S., Oliveira, E.L., Campos, D.A. and Barros, A.C.S.A. (2016) Efeito da adubação silicatada na qualidade da fibra do algodoeiro. MAGISTRA, 28, 244-253.

[4] Ulloa, M., Brubaker, C. and Chee, P. (2010) Cotton. In: Kole, C., Ed., Genome Mapping and Molecular Breeding in Plants (vol. 6, pp. 1-50). Berlin Heidelberg: Springer-Verlag. https://doi.org/10.1007/978-3-540-34538-1_1

[5] Muhammad, A., Muhammad, A.U. and Atif, A. (2014) Identification of Cotton Properties to Improve Yarn Count Quality by Using Regression Analysis. Pakistan Journal of Scientific and Industrial Research Series A: Physical Sciences 57, 167-171.

[6] Komoroski, R.A. (1986) High Resolution NMR Spectroscopy of Synthetic Polymers in Bulk. VCH-Verlagsgesellschaft, Weinheim, Deerfield Beach, Florida.

[7] McBrierty, V.J. and Packer, K.J. (2006) Nuclear Magnetic Resonance in Solid Polymers. Cambridge University Press, Cambridge.

[8] Levitt, M.H., Grant, D.M., Harris, R.K. and Wiley, J. (2002) Encyclopedia of Magnetic Resonance. Encyclopedia of Nuclear Magnetic Resonance.

[9] Monteiro, M.S.S.B., Cucinelli Neto, R.P. and Santos, I.C.S. (2012) Inorganic-Organic Hybrids Based on Poly ( $\varepsilon$-Caprolactone) and Silica Oxide and Characterization by Relaxometry Applying Low-Field NMR. Materials Research, 15, 825-832. https://doi.org/10.1590/S1516-14392012005000121

[10] Atalla, R.H., Gast, J.C., Sindorf, D.W., Bartuska, V.J. and Maciel, G.E. (1980) Carbon-13 NMR Spectra of Cellulose Polymorphs. Journal of the American Chemical Society, 102, 3249-3251. https://doi.org/10.1021/ja00529a063 